\title{
RANCANG BANGUN KEAMANAN TRANSFER DATA VOIP OVER VPN PADA SISTEM OPENSOURCE TRIXBOX
}

\author{
Oleh \\ I Wayan Eka Putra Darmawan \\ Jurusan Pendidikan Teknik Informatika
}

\begin{abstract}
ABSTRAK
VoIP (Voice over Internet) dikenal juga dengan sebutan IP (Internet Protocol) Telephony saat ini semakin banyak digunakan karena memiliki beberapa keunggulan, salah satu diantaranya yaitu tarif yang jauh lebih murah daripada tarif telepon tradisional sehingga pengguna telepon dapat memilih layanan tersebut sesuai dengan kebutuhannya. VoIP dapat mereduksi biaya percakapan sampai $70 \%$. Selain memiliki beberapa keunggulan di atas, VoIP juga memiliki kelemahan yang sangat vital yaitu dari segi keamanan transfer suara karena berbasis IP, sehingga siapapun bisa melakukan penyadapan dan perekaman terhadap data VoIP. Ganguan yang terjadi pada sistem VoIP ada berbagai macam diantaranya, transfer data yang lewat pada suatu jaringan seperti misalnya dapat disalahgunakan (abuse), dapat dibajak isi data tersebut (sniffing), dan tidak dapat mengakses server dikarenakan server yang kelebihan muatan (Denial of Services).

Ada beberapa cara untuk mengamankan komunikasi data VoIP, antara lain, dengan mengamankan jalur yang digunakan pengguna untuk melakukan komunikasi VoIP dengan menggunakan metode VPN (Virtual Private Network) dan juga dapat dilakukan suatu metode kriptografi pada aplikasi VoIP tersebut sehingga data yang dikirimkan dapat dilindungi dengan baik. VPN adalah teknik pengaman jaringan yang bekerja dengan cara membuat suatu tunnel sehingga jaringan yang dipercaya dapat menghubungkan jaringan yang ada di luar melalui internet. Titik akhir dari VPN adalah tersambungnya Virtual Channels (VCs) dengan cara pemisahan. Kenyataannya koneksi sebuah end-to-end VPN tergantung dari sebuah nilai dari hubungan daripada titik-titiknya. VPN mempunyai dua metode dalam pengamanan yakni IPSec dan Crypto IP Encapsulation (CIPE). Selain itu dapat dipergunakan teknik Kriptografi (cryptography) yang merupakan ilmu dan seni penyimpanan pesan, data, atau informasi secara aman.

Sistem VoIP menggunakan VPN ini diharapkan dapat memberikan keamanan transfer data pada jaringan internet maupun intranet.
\end{abstract}

Kata-kata kunci: Voice over Internet, Virtual Private Network, Sniffing.

\begin{abstract}
VoIP (Voice over Internet) also known as IP (Internet Protocol) telephony is increasingly being used because it has several advantages, one of them is far cheaper rates than traditional phone rates so that phone users can choose the service appropriate to their needs. VoIP can reduce costs up to $70 \%$ conversation. In addition to having several advantages over, VoIP also has a vital weakness is in terms of security for IP-based voice transfer, so anyone can conduct wiretapping and recording of VoIP data. Disturbance occurs
\end{abstract}

Rancang Bangun Keamanan Transfer Data...........(I Wayan Eka Putra Darmawan) 
in the system there are various kinds such as VoIP, data transfer via a network such as for example can be abused (abuse), can be hijacked by the contents of the data (sniffing), and can not access the server because the server is overloaded (Denial of Services).

There are several ways to secure data communications VoIP, among others, to secure the route used by users to make VoIP communications using a VPN (Virtual Private Network) and can also be a method of cryptography in applications such VoIP so that transmitted data can be well protected. VPN is a network of safety technique that works by making a tunnel to a trusted network can connect networks that exist outside the Internet. End point of the VPN is tersambungnya Virtual Channels (VCs) by way of separation. In fact a connection end-to-end VPN hanging from a value from the relationship than the dots. VPN has two methods, namely security and IPSec Crypto IP Encapsulation (CIPE). Moreover, it can be used cryptography techniques (cryptography), which is the science and art of message storage, data, or information securely.

VoIP systems use a VPN is expected to provide security of data transfer on the Internet or intranet network.

Key words: Voice over the Internet, Virtual Private Network, Sniffing.

\section{PENDAHULUAN}

Voice over Internet Protocol yang disingkat dengan VoIP, dikenal juga dengan sebutan IP (Internet Protocol) Telephony. VoIP didefinisikan sebagai suatu sistem yang menggunakan jaringan internet atau intranet untuk mengirimkan data paket suara dari suatu tempat ke tempat yang lain menggunakan perantara protokol IP. Perbedaan VoIP dengan telepon tradisional terletak pada masalah infrastrukturnya. VoIP menggunakan internet atau intranet sedangakan telepon tradisional menggunakan infrastruktur telepon yang sudah dibangun lebih awal (Winarno, 2008). Teknologi VoIP memiliki beberapa keunggulan, salah satu diantaranya yaitu tarif yang jauh lebih murah daripada tarif telepon tradisional sehingga pengguna telepon dapat memilih layanan tersebut sesuai dengan kebutuhannya. VoIP dapat mereduksi biaya percakapan sampai 70\% (Apri, 2009). VoIP telah berhasil memposisikan diri sebagai salah satu kandidat teknologi terbaik pengganti POTS (Plain Old Telephone Systems). VoIP terdiri dari dua komponen yaitu server dan client. Server VoIP berfungsi sebagai basis pemrosesan suara, sedangkan client berfungsi sebagai end user yang melakukan komunikasi. VoIP Phone System berbasiskan sistem opensource, dimana yang poluler digunakan adalah Trixbox. Hal ini dikarenakan Trixbox dapat mengkombinasikan paket-paket opensource telepon terbaik yang disertakan di dalam sistem operasi tersebut. Selain memiliki beberapa keunggulan di atas, VoIP juga memiliki kelemahan yang sangat vital yaitu dari segi keamanan transfer suara karena berbasis IP, sehingga siapapun bisa melakukan penyadapan dan perekaman terhadap data VoIP. Berikut adalah contoh sniffing

JPTK, UNDIKSHA, Vol. 11, No. 1, Januari $2014: 1$ - 12 
yang dilakukan pada jaringan VoIP STT Telkom, cracker mengunakan metoda tapping dengan menggunakan software berbasis windows yaitu cain and abel. Ketika client VoIP berkomunikasi, data yang melewati jaringan VoIP disadap dan disalahgunakan oleh cracker sehingga sangat menggangu privasi dari pengguna jaringan VoIP STT Telkom. Pada Gambar 1.1 adalah proses penyadapan data yang dilakukan pada jaringan VoIP STT Telkom. (STT Telom, 2007)

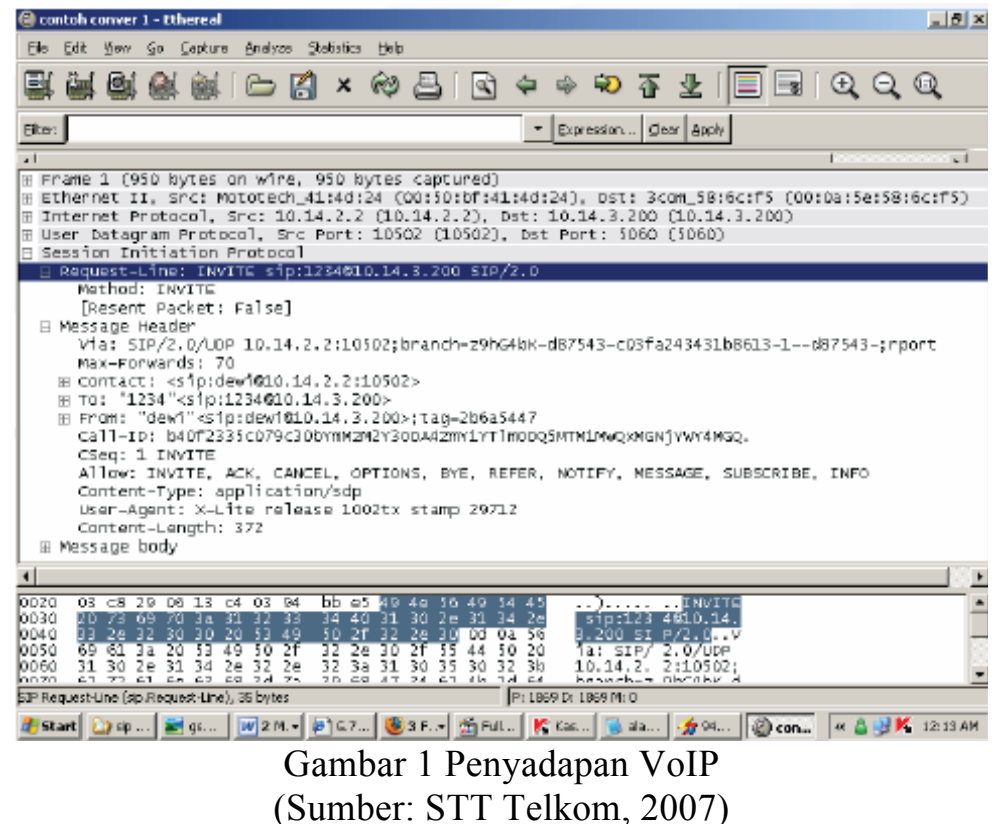

Teknologi VoIP semakin banyak digunakan, tapi teknik keamanan yang digunakan untuk melindungi data hanya beberapa. Adapun macam-macam gangguan (threats) data yang lewat pada suatu jaringan seperti misalnya dapat disalahgunakan (abuse), dapat dibajak isi data tersebut (sniffing), dan tidak dapat mengakses server dikarenakan server yang kelebihan muatan (Denial of Services). Ada beberapa cara untuk mengamankan komunikasi data VoIP, antara lain, dengan mengamankan jalur yang digunakan pengguna untuk melakukan komunikasi VoIP dengan menggunakan metode VPN (Virtual Private Network) dan juga dapat dilakukan suatu metode kriptografi pada aplikasi VoIP tersebut sehingga data yang dikirimkan dapat dilindungi dengan baik. VPN adalah teknik pengaman jaringan yang bekerja dengan cara membuat suatu tunnel sehingga jaringan yang dipercaya dapat menghubungkan jaringan yang ada di luar melalui internet.

Berdasarkan permasalahan yang telah dijelaskan di atas, maka penulis pada penelitian ini mencoba membuatkan sebuah penelitian dengan judul "Rancang Bangun 
Keamanan Teransfer Data VoIP over VPN pada Sistem Opensource Trixbox. Adapun rumusan masalah yang akan dikaji dalam penelitian ini yaitu bagaimana me rancang dan membangun keamanan teransfer data suara VoIP over VPN pada sistem opensource trixbox?

\section{METODE PENELITIAN}

Metode yang digunakan dalam penelitian ini adalah metode Software Development Life Cycle (SDLC) dengan Waterfall-based Model. Pada Gambar 2 dan Gambar 3 dapat dilihat alur pengembangan sistem.

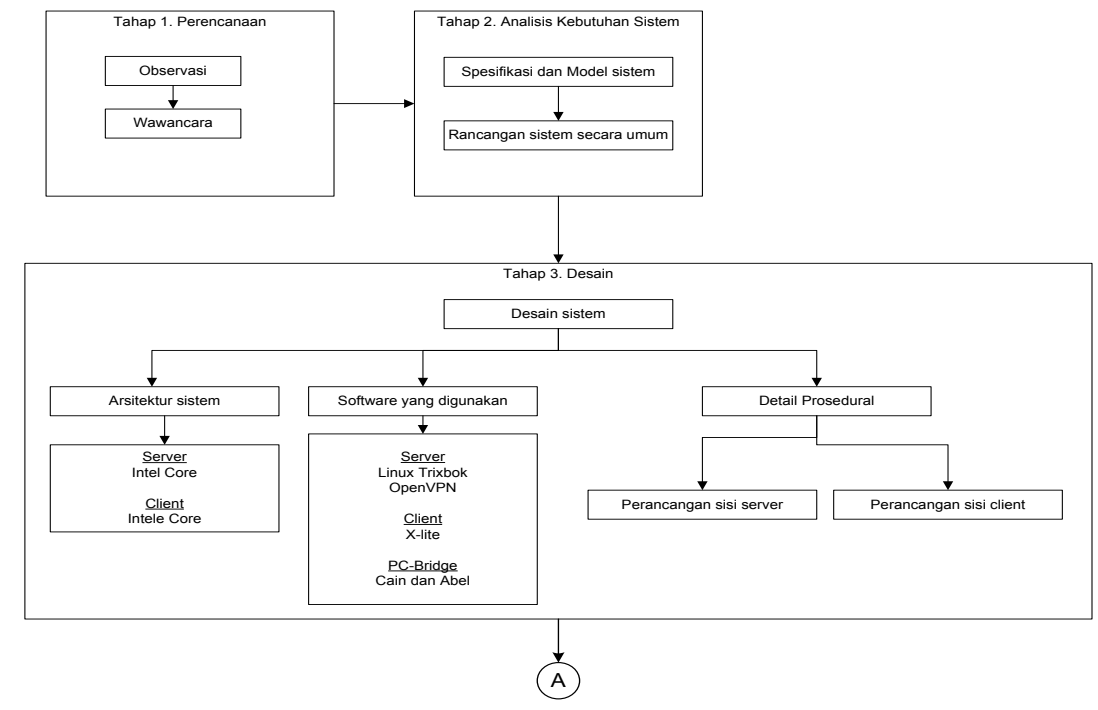

Gambar 2 Bagan pengembangan sistem

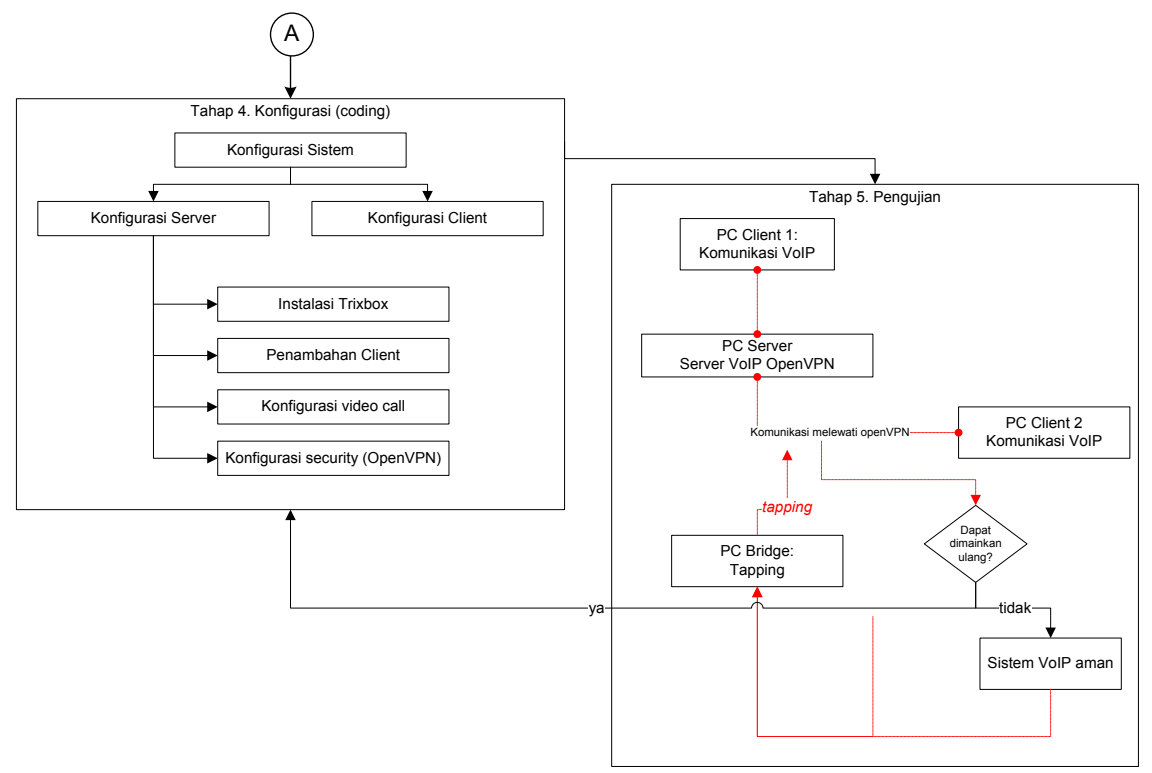

Gambar 3 Bagan pengembangan sistem (lanjutan Gambar 2.)

JPTK, UNDIKSHA, Vol. 11, No. 1, Januari 2014 : 1 - 12 
Gambar 2 dan Gambar 3 menunjukan alur dari pengembangan sistem yang dibedakan menjadi beberapa tahap sebagai berikut.

\section{Tahap 1. Perencanaan}

Tahap perencanaan dimulai dengan melakukan observasi dan wawancara mengenai permasalahan keamanan transfer data pada saat melakukan komunikasi via VoIP.

\section{Tahap 2. Analisis kebutuhan sistem}

Dari permasalahan yang ditemukan pada tahap perencanaan penulis membuat spesifikasi dan model dari kebutuhan pemakai sistem dan membuat alternatif-alternatif rancangan sistem secara umum.

\section{Tahap 3 Desain}

Proses desain akan menerjemahkan syarat kebutuhan sistem ke sebuah perancangan sistem yang dapat diperkirakan sebelum konfiguarsi dan coding sistem. Proses ini berfokus pada arsitektur sistem, software yang digunakan dan detail prosedural sistem

\section{Tahap 4 Konfigurasi (coding)}

Pada tahap ini akan dilakukan konfigurasi sistem, dimana merupakan proses realisasi dari desain yang dibuat ke dalam sistem yang dibangun.

\section{Tahap 5 Pengujian}

Proses pengujian dilakukan dengan melakukan analisis performansi keamanan serta perubahannya sebelum dan sesudah ditambahkan aplikasi VPN. Untuk membantu analisis keamanan, digunakan alat bantu yaitu software cain dan abel. Software berbasis windows ini akan menangkap semua paket yang lewat dan melakukan analisis keamanan terhadap data VoIP. Software ini akan di pasang pada $P C$ bridge dan menangkap setiap paket yang melewatinya. Selain itu akan dianalisis isi dari paket tersebut untuk menganalisa celah keamanan lainnya. Skenario yang dibuat adalah VoIP client 1 dan 2 akan berkomunikasi dengan menggunakan salah satu codec. Kemudian data yang lewat tersebut akan di tapping oleh cain dan abel. Adapun hasil dari tapping akan dicoba untuk dimainkan ulang. Apakah rekaman data VoIP tersebut dapat dimainkan ulang, jika ya berarti VoIP menggunakan SIP tidak aman dalam implementasinya dan penulis akan kembali melakukan konfigurasi ulang (kembali ke tahap 4. Konfiguarasi (coding). Jika rekaman data tidak dapat dimainkan ulang maka sistem VoIP over VPN sudah aman.

Instrumen yang digunakan untuk analisis sistem adalah berupa angket, untuk lebih jelasnya dapat dilihat pada tabel 1 , tabel 2 , tabel 3 , dan tabel 4 
Tabel 1. Pengujian koneksi

\begin{tabular}{|c|c|c|c|c|}
\hline \multirow[t]{2}{*}{ No } & \multirow[t]{2}{*}{ Mekanisme pengujian } & \multirow{2}{*}{$\begin{array}{l}\text { Indikator } \\
\text { pengujian }\end{array}$} & \multicolumn{2}{|c|}{ Hasil Pengujian } \\
\hline & & & $\mathrm{Ya}$ & Tidak \\
\hline 1 & $\begin{array}{l}\text { Komputer server } \\
\text { maupun komputer } \\
\text { client menjalankan } \\
\text { perintah "ping } \\
\text { 127.0.0.1" }\end{array}$ & $\begin{array}{l}\text { Ketika } \\
\text { menjalankan } \\
\text { perintah ping } \\
\text { apakah muncul } \\
\text { tampilan seperti } \\
\text { gambar 3.3 }\end{array}$ & & \\
\hline
\end{tabular}

Tabel 2. Pengujian server

\begin{tabular}{|c|c|c|c|c|}
\hline \multirow[t]{2}{*}{ No } & \multirow[t]{2}{*}{ Mekanisme pengujian } & \multirow{2}{*}{$\begin{array}{l}\text { Indikator } \\
\text { pengujian }\end{array}$} & \multicolumn{2}{|c|}{ Hasil Pengujian } \\
\hline & & & Ya & Tidak \\
\hline 1 & $\begin{array}{l}\text { Komputer server } \\
\text { booting dengan normal } \\
\text { sampai proses berakhir } \\
\text { ditandai dengan } \\
\text { muculnya halaman } \\
\text { login pada layar } \\
\text { monitor }\end{array}$ & $\begin{array}{l}\text { Layar monitor } \\
\text { muncul tampilan } \\
\text { awal login user }\end{array}$ & & \\
\hline 2 & $\begin{array}{l}\text { Komputer server dapat } \\
\text { dikonfigurasi melalui } \\
\text { remote web base } \\
\text { sampai ke tahap } \\
\text { halaman login user }\end{array}$ & $\begin{array}{l}\text { User bisa } \\
\text { membuka } \\
\text { halaman login } \\
\text { user melalui } \\
\text { halaman web }\end{array}$ & & \\
\hline 3 & $\begin{array}{l}\text { Komputer server dapat } \\
\text { menambahkan serta ter- } \\
\text { register extension dari } \\
\text { VoIP client ketika } \\
\text { dikonfigurasi melalui } \\
\text { remote web base }\end{array}$ & $\begin{array}{l}\text { Administrator } \\
\text { dapat } \\
\text { menambahkan } \\
\text { VoIP extension }\end{array}$ & & \\
\hline 4 & $\begin{array}{l}\text { Komputer server dapat } \\
\text { menjalankan OpenVPN } \\
\text { Server }\end{array}$ & $\begin{array}{l}\text { OpenVPN dapat } \\
\text { dijalankan } \\
\text { dengan baik }\end{array}$ & & \\
\hline
\end{tabular}

Tabel 3. Pengujian client

\begin{tabular}{|c|l|l|l|l|}
\hline No & Mekanisme pengujian & \multicolumn{1}{|c|}{$\begin{array}{l}\text { Indikator } \\
\text { pengujian }\end{array}$} & \multicolumn{2}{|c|}{ Hasil Pengujian } \\
\cline { 4 - 5 } & & \multicolumn{1}{|c|}{ Ya } & Tidak \\
\hline 1 & VoIP client atau & PC client & & \\
& softphone $x$-lite sudah & sudah terinstal & & \\
& terinstal dengan benar & X-Lite & & \\
\hline
\end{tabular}

JPTK, UNDIKSHA, Vol. 11, No. 1, Januari 2014 : 1 - 12 


\begin{tabular}{|l|l|l|l|l|}
\hline 2 & di PC client & $\begin{array}{l}\text { VoIP client } \\
\text { bisa terhubung } \\
\text { ke server VoIP }\end{array}$ & & \\
$\begin{array}{l}\text { Voregistent } \text { sudah } \\
\text { dan siap mengan baik } \\
\text { panggilan }\end{array}$ & & \\
\hline
\end{tabular}

Tabel 4. Pengujian Kemanan VoIP over VPN

\begin{tabular}{|l|l|l|l|l|}
\hline No & Mekanisme pengujian & \multicolumn{1}{|c|}{$\begin{array}{c}\text { Indikator } \\
\text { pengujian }\end{array}$} & \multicolumn{2}{|c|}{ Hasil Pengujian } \\
\cline { 4 - 5 } & & & Ya & Tidak \\
\hline 1 & PC client 1 berkomikasi & Transfer data & & \\
& dengan PC client 2 & antara pc client & & \\
& menggunakan openVPN & 1 dan 2 dapat & & \\
& dan PC brige melakukan & di tangkap oleh & & \\
& sniffing dengan & pc brige dan & & \\
& software cain dan abel & dimainkan & & \\
& & ulang & & \\
\end{tabular}

\section{HASIL DAN PEMBAHASAN}

Dalam pembuatan sistem jaringan IP telephony atau VoIP akan dilakukan prosedur operasi dan pengujian yang mengacu pada desain perancangan. Ada beberapa tahap yang harus dilakukan yaitu sebagai berikut:

1. Konfigurasi pada sisi server
a. Instalasi Trixbox
b. Penambahan Client
c. Konfigurasi Video Call
d. Konfigurasi Security

2. Konfigurasi pada sisi client

3. Pengujian pada sisi server

4. Pengujian pada sisi client

5. Pengujian sistem

Implementasi dan prosedur operasi pada jaringan IP telephony atau VoIP sistem akan dilakukan sesuai dengan langkah-langkah di atas. Pada pengujian sistem akan dilakukan beberapa pengujian agar sistem bisa diketahui dapat berjalan dengan normal serta dapat dianalisa keamanan dalam IP telephony tersebut. Pada gambar 4bisa dilihat pemetaan dari jaringan yang akan dibuat.

Rancang Bangun Keamanan Transfer Data...........(I Wayan Eka Putra Darmawan) 


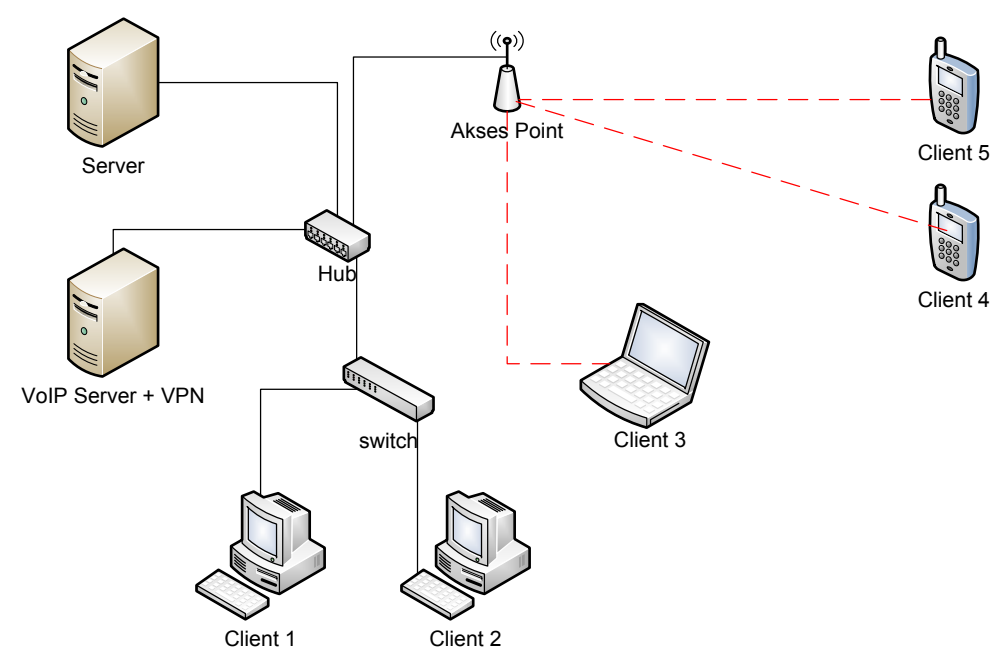

Gambar 4 Pemetaan Jaringan VoIP.

Spesifikasi dari kebutuhan hardware dan software komputer server dan komputer client bisa dilihat pada Tabel 5

Tabel 5 Dafar Perangkat

\begin{tabular}{|l|l|l|l|l|l|}
\hline No & Jenis Perangkat & Interface & IP & $\begin{array}{l}\text { Sistem } \\
\text { Operasi }\end{array}$ & $\begin{array}{l}\text { Aplikasi yang } \\
\text { digunakan }\end{array}$ \\
\hline 1 & VoIP Server & Eth0 & 11.11 .1 .4 & $\begin{array}{l}\text { Linux } \\
\text { Trixbox }\end{array}$ & $\begin{array}{l}\text { Asterisk } \\
\text { OpenVPN }\end{array}$ \\
\hline 2 & $\begin{array}{l}\text { Dua komputer } \\
\text { VoIP client }\end{array}$ & Eth0 & $\begin{array}{l}11.11 .1 .100 \\
11.11 .1 .101\end{array}$ & $\begin{array}{l}\text { Microsoft } \\
\text { Windows } \\
\text { Seven }\end{array}$ & Softphone X-LIte \\
\hline 3 & $\begin{array}{l}\text { Dua Handphone } \\
\text { ber-wifi }\end{array}$ & Mobile Wifi & 11.11 .1 .102 & $\begin{array}{l}\text { Symbian 9 } \\
\text { versi 3 }\end{array}$ & SIP Connection \\
\hline 4 & PC bridge & Eth0 & 11.11 .1 .103 .1 .104 & $\begin{array}{l}\text { Microsoft } \\
\text { Windows } \\
\text { Seven }\end{array}$ & Cian dan Abel \\
\hline
\end{tabular}

Pengujian keamanan dengan cara penyadapan terhadap panggilan VoIP yang sedang berjalan dalam jaringan lokal. Langkah-langkahnya adalah sebagai berikut :

a. PC yang berfungsi sebagai penyadap ditambahkan program Cain \& Able yang diambil dari http://www.oxid.it/. Langkah-langkah instalasi secara detail dapat dilihat pada lampiran.

b. Ketika panggilan sedang berlangsung dari client 1 menuju client 2 alur data pada jaringan ditunjukkan dengan garis merah pada Gambar 5. Komputer pada client1 akan mengirimkan data menuju server untuk dilanjutkan dari server menuju client2.

JPTK, UNDIKSHA, Vol. 11, No. 1, Januari $2014: 1$ - 12 


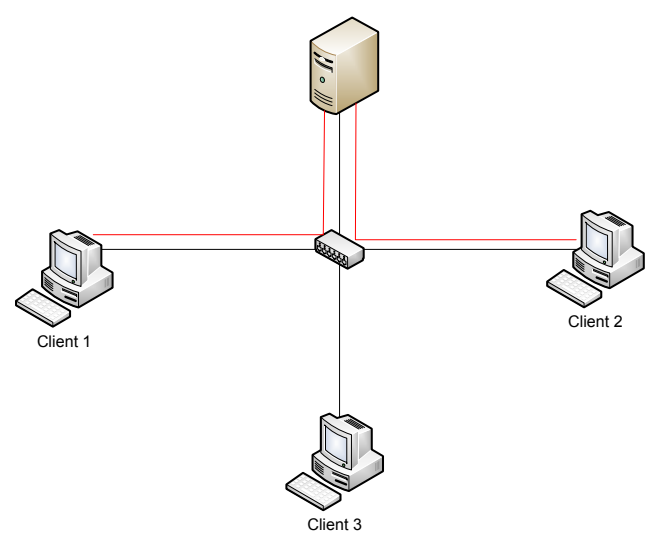

Gambar 5 Alur Data Panggilan

c. Ketika data akan disadap komunikasi antara client 1 menuju server akan dialihkan terlebih dahulu menuju client 3 (sniffer) dan baru akan diteruskan menuju server. Begitu juga proses antara client 2 menuju server akan dialihkan terlebih dahulu menuju client 3 (sniffer). Sehingga data percakapan client 1 dan client 2 akan disadap oleh client 3 seperti pada Gambar 6

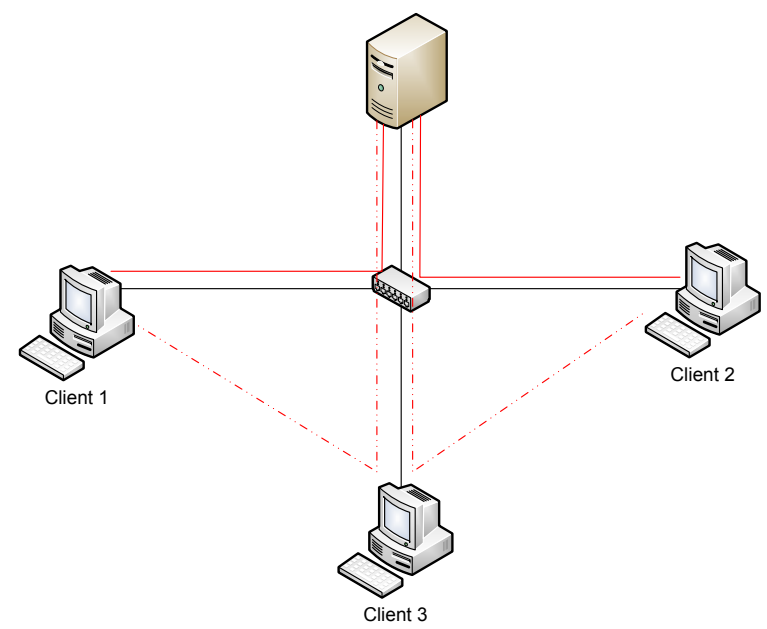

Gambar 6 Penyadapan Data

Cara penyadapan yang dilakukan client 3 adalah dengan langkah-langkah sebagai berikut :

a. Pembukaan program cain abel pada Start Menu $>$ All Program $>$ Cain

b. Aktifkan proses sniffing dan ARP poison routing dengan menekan start sniffer dan start poison routing seperti pada Gambar $7 .$. 


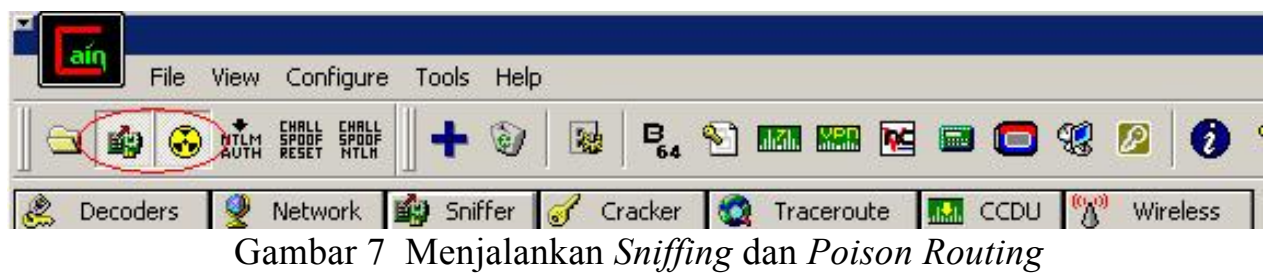

c. Pada program Cain buka tab Sniffer $>$ Host kemudian pilih add host pada tool bar. Maka akan muncul dialog box untuk me-scan IP komputer VoIP client yang lain dalam jaringan.

d. Pada tab sniffer pilih sub tab ARP. Tambahkan host yaitu host dari sisi server dan client yang akan disadap kemudian pilih tab sniffer $>$ VoIP untuk melihat komunikasi VoIP yang sedang berjalan.

e. Contoh penyadapan yang dilakukan pada server VoIP dapat dilihat pada gambar 8.

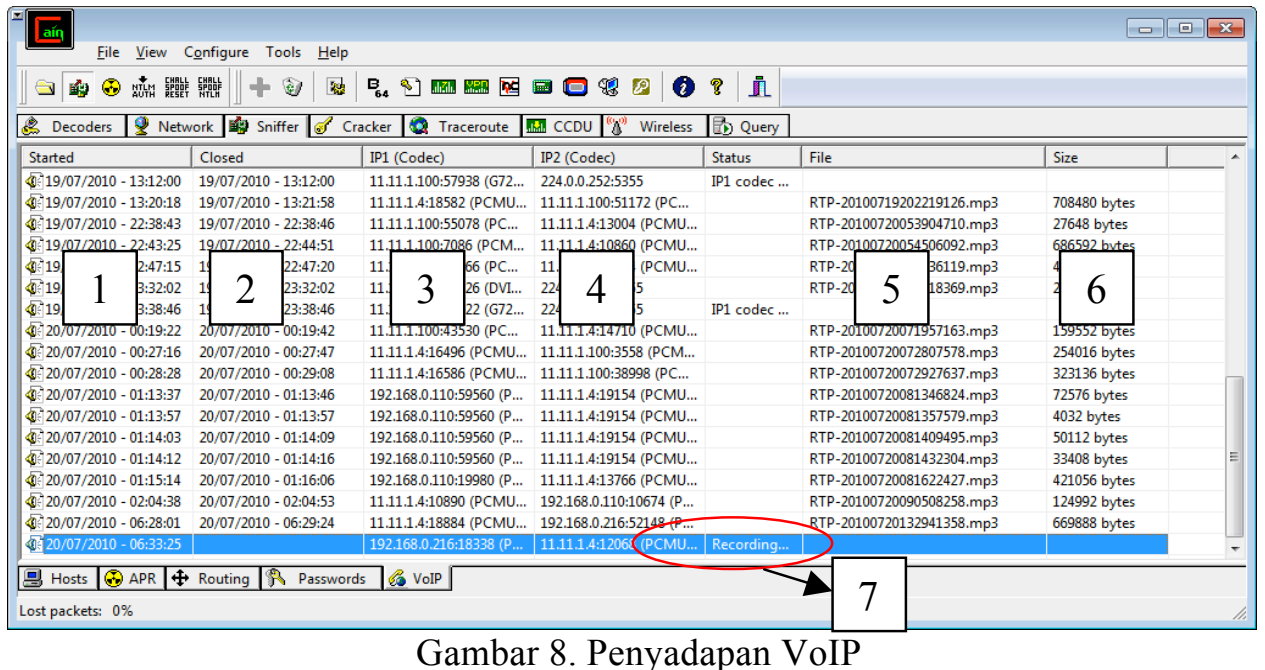

Gambar 8 adalah proses penyadapan komunikasi VoIP dengan software Cain dan Abel. Berikut adalah penjelasan angka yang tertera pada gambar.

a) Nomor 1, menunjukan tanggal dan waktu dimulainya komunikasi melalui jaringan VoIP.

b) Nomor 2, menunjukan tanggal dan waktu berakhirnya percakapan yang dilakukan melalui jaringan VoIP.

c) Nomor 3, menunjukan alamat IP dari VoIP client 1 yang melakukan panggilan ke VoIP client 2. 
d) Nomor 4, menunjukan alamt IP dari VoIP client 2 yang merupakan penerima telepon dari VoIP client 1.

e) Nomor 5, adalah jenis codec yang dihasilkan dari penyadapan komunikasi antara client 1 dan client 2 , yang bisa dimainkan ulang oleh penyadap.

f) Nomor 6, menunjukan ukuran file codac yang tersimpan di komputer penyadap.

g) Nomor 7, adalah proses penyadapan ditandai dengan tanda recording saat proses percakapan terjadi antara client 1 dan client 2 .

Pengujian keamanan dilakukan kembali dengan melakukan sniffing untuk membuktikan bahwa jaringan menggunakan VPN bersifat lebih aman. Gambar 9. menunjukan software cain dan abel tidak dapat menangkap alur komunikasi yang terjadi pada sistem VoIP.

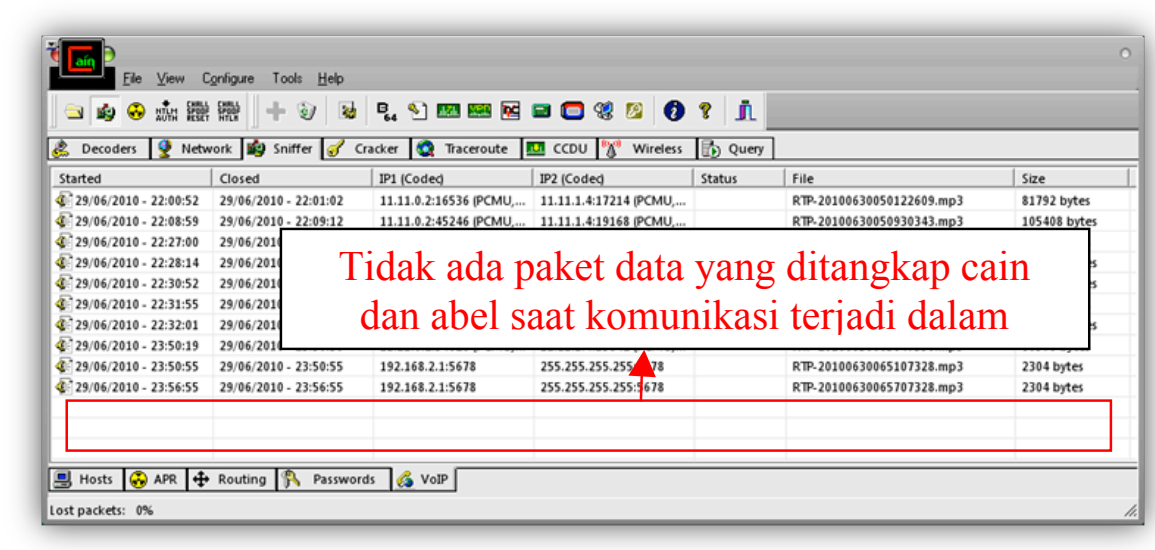

Gambar 9. Tampilan cain dan abel yang tidak bisa menangkap transfer data yang berlangsung dijaringan VoIP

\section{PENUTUP}

Berdasarkan hasil analisis data dan pembahasan pada penelitian ini, maka dapat diambil simpulan yaitu : (1)Secara garis besar sistem operasi trixbox sudah dapat digunakan untuk menangani jaringan IP telephony, namun ketika dilakukan penyadapan dengan menggunakan program cain able terbukti komunikasi suara dapat terekam sehingga privasi dari pengguna VoIP kurang terjamin.Untuk mengatasi penyadapan, maka diberi salah satu alternatif pengamanan dengan melakukan penambahan VPN server pada trixbox, serta penambahan VPN client pada sisi client VoIP sehingga trafik VoIP dilewatkan melalui koneksi VPN.(2) Penggunaan VPN menjadikan sistem VoIP aman dikarenakan adanya autentikasi antara server dan client ketika akan melakukan koneksi, serta pemberian enkripsi

Rancang Bangun Keamanan Transfer Data...........(I Wayan Eka Putra Darmawan) 
pada data yang akan dikirim.(3) Penggunaan VPN tidak mempengaruhi kemampuan komunikasi VoIP dalam jaringan lokal.

Berdasarkan pengamatan penulis, terdapat beberapa hal yang dapat dijadikan bahan pertimbangan untuk ditindak lanjuti diantaranya: (1) Penggunaan VoIP merupakan solusi alternatif komunikasi masa depan, oleh karena itu untuk pengembangan selanjutnya dapat dilakukan analisis performansi VoIP dengan VoIP monitoring. (2) Disarankan untuk penggunaan VPN dalam jaringan internet agar lebih memperhatikan delay dari transfer suara VoIP. (3) Bagi pengguna yang ingin menghubungkan VoIP dengan telepon konvensional disarankan untuk menambahkan modul telepon gateway.

\section{DAFTAR PUSTAKA}

Farhan Perdana, 2007. "Sniffing? Cain \& Abel Saja!". Tersedia pada http://ilmukomputer.org/2007/03/27/sniffing-cain-abel-saja/ (diakses tanggal 10 Maret 2010).

Rossadhi S. Sany, 2009. "Teknik Keamanan Voice over WLANs 802.11". Universitas Sumatra Utara.

Sugeng Winarno, 2008. ”Membangun Telepon Berbasis VoIP”. Bandung: Informatika.

JPTK, UNDIKSHA, Vol. 11, No. 1, Januari $2014: 1$ - 12 